\title{
Using Fan Passion to Investigate Constraints to Student Attendance at College Football Games
}

\author{
Jason M. Simmons \\ University of Cincinnati
}

\author{
Nels K. Popp \\ University of North Carolina
}

\section{Chad D. McEvoy and Steven M. Howell \\ Northern Illinois University}

\begin{abstract}
Given the decline in average student attendance at college football games nationwide, it is important for marketers to understand the constraints inhibiting student attendance. The current study addresses this issue by testing for differences in constraints affecting student nonattendance decisions based on their passion for the home team. Data were collected from students not attending games on six college campuses during actual football games. A total of 33 potential constraints to attendance were assessed. Results indicated statistically significant differences among intrapersonal, event-specific, and marketing-related constraints. Regardless of passion level, prior commitments to school and work were among the most highly-rated constraints to attendance. For highly-passionate fans, beverage costs, poor team performance, and watching the game on television were also highly-rated constraints. Low-passion fans, however, were constrained by time commitment necessary to attend, as well as lack of interest in football.
\end{abstract}

Keywords: barriers, fandom, inhibitors, leisure

As Trail, Robinson, Dick, and Gillentine (2003) note, fans with different levels of identification, or passion, attend sporting events for different reasons. Take the following hypothetical scenario: Jordan is a student at Midwestern University (MU). He has been a fan for as long as he can remember, having attended football games with his dad since he was a little kid. Jordan follows multiple MU-related social media accounts, and lives and dies by the team's wins and losses. Bailey, on the other hand, is also a student at MU. She is not really a football fan, but supports the team because it represents her school. The main 
reason she attends games is because her friends like to go, but she really gets into the games if it is close in the fourth quarter.

From this brief example, it is clear Jordan is highly passionate about MU football, while Bailey is much less so. This passion drives their motivations to attend, affects how they feel about the team, and influences how frequently each thinks about the team (Wakefield, 2016). For sport marketers, Jordan and Bailey represent distinct fan segments, each with their own wants and needs, and unique drivers of game attendance.

The practice of segmenting sport fans on the basis of their level of fandom is not new to sport marketing research (Stewart, Smith, \& Nicholson, 2003). Numerous studies have considered differences in fans, and their associated consumptive behaviors, on the basis of identification (James \& Trail, 2008; Wann \& Branscombe, 1993), avidity (Hong, 2009), allegiance (Funk \& James, 2001), and emotional attachment (Koo, Andrew, Harden, \& Greenwell, 2009), among other factors. More recently, Wakefield (2016) developed a measure of fan passion for use as a segmentation tool, finding passion was a stronger predictor of fan attendance, media consumption, and social media activity than established measures of fan identification (Wann \& Branscombe, 1993), social identity (Mael \& Ashforth, 1992), and fan/team relationship quality (Kim, Trail, \& Ko, 2011), as well as single-item measures of avidity and fandom.

While Jordan and Bailey differ on what motivates them to attend, marketers would be remiss to ignore the factors causing them not to attend games. Such barriers, or constraints, may inhibit someone from attending a game, even if they are motivated to attend (Trail \& Kim, 2011). Jordan, for example, may often forgo school work or brave harsh weather conditions to attend an MU football game, but at times he perceives food and beverages at the games to be too costly, and opts instead to watch from the comfort of his dorm room on his high definition television. Bailey, meanwhile, enjoys a close match-up, but sometimes feels games last too long and can become boring. In addition, she is frustrated with cellphone and Wi-Fi service within MU's stadium. Understanding these constraints, and, in particular, how such constraints influence fans with differing degrees of passion for the team, allows marketers to tailor their product and messaging to aid different fan segments in negotiating the constraints they may face.

College students, such as Jordan and Bailey, are an especially appropriate sample by which to assess the effect of fan passion on constraints. According to a Wall Street Journal report that accessed longitudinal student attendance data from 80 Football Bowl Subdivision (FBS) universities, student attendance at major college football games declined at a nationwide average of $7.1 \%$ during a 5-year stretch from 2009-2013 (Cohen, 2014). Little has changed since that Wall Street Journal report, as schools across the country-from Missouri State to Texas to Clemson-are still struggling to reverse this trend (Cowlishaw, 2018; Raynor, 2017; Wheeler, 2017). These numbers are concerning to collegiate athletics marketers as students are often considered the next crop of season ticket holders and donors, and contribute to the atmosphere inside the venue (Tracy, 2016). Therefore, the current study seeks to address this trend by assessing constraints impacting college student nonattendance at football games, and how the intensity of such constraints varies based on one's passion for their school's team. 


\section{Fan Passion}

The concept of fan passion stems from Vallerand et al. (2003), who defined passion as "a strong inclination toward an activity that people like, that they find important, and in which they invest time and energy" (p. 757). Such activities are then internalized and "come to be so self-defining that they represent central features of one's identity" (Vallerand, 2008, p. 2). Much of Vallerand and colleagues' work on passion centers on distinguishing passion as either harmonious or obsessive in nature (e.g., Donahue, Rip, \& Vallerand, 2009; Vallerand et al., 2003, 2008; Vallerand, Rousseau, Grouzet, Dumais, Grenier, \& Blanchard, 2006; VernerFilion, Lafreniere, \& Vallerand, 2012). Harmonious passion for an activity is characterized by autonomy, both in terms of internalization and willingness to participate. Conversely, individuals exhibiting obsessive passion for an activity are unable to control their desires to participate, due in part to intra/interpersonal pressures to maintain social standing and/or self-esteem, and may participate at the expense of other roles and activities (Vallerand et al., 2003, 2006).

Wakefield (2016) recently introduced a different perspective on passion, framing it as a marketing construct, arguing "the intensity of passion" (p. 230) is a determinant of fan consumption, and should be used by sport marketers as a segmentation tool to compare fans. Those who are more passionate about a team, according to Wakefield, not only consume sport at a higher level, but are also more consumed by sport. Thus, if fans are segmented based on the intensity of their passion for a team, the resulting subsets will be more homogenous and more receptive to messages designed for each group. The question now turns to how passion differs from more established sport marketing constructs such as identification, allegiance, and attachment.

According to sport marketing scholars, identity and attachment share a common tie in that both reflect cognitive orientations of the self in relationship to a team. Wann, Melnick, Russell, and Pease (2001), for example, defined team identification as "the extent to which a fan feels psychologically connected to a team" (p. 3). Funk and James (2001), as part of their Psychological Continuum Model (PCM), referred to attachment as "a stable psychological connection" (p. 132) to a team. Allegiance, the next stage of the PCM, denotes a strengthening of one's attachment to the team with attitudinal loyalty. Vallerand and colleagues' (2003) conceptualization and measurement of passion, on the other hand, taps into a fan's heart, mind, body, and soul (Wakefield, 2016). As Wakefield describes:

An individual with a passion toward a team would feel strong positive emotions about the team and its players (heart), frequently think about various aspects of the team such as games, teams, players, statistics ... (mind), spend considerable time participating in related consumption ... (body), and place a high priority on the team in life relative to other pursuits (soul). (p. 231)

Perhaps more important, beyond differences in definition, Wakefield (2016) found fan passion to be a better predictor of sport consumptive-related activities than previously established measures of identification (Wann \& Branscombe, 1993), social identity (Mael \& Ashforth, 1992), relationship quality (Kim et al., 2011), and involvement (Zaichkowsky, 1985). For each of (a) game attendance, 
(b) team-related media consumption, and (c) team-related social media usage, fan passion was the strongest predictor in the model, and in the case of attendance, the remaining measures failed to explain any significant additional variance. Indeed, Wakefield contends not only is fan passion a distinct construct, but passion is what motivates or drives one's avidity, identification, or commitment with a team. This sentiment is echoed by Vallerand et al. (2008) and Vallerand (2008).

Wakefield's (2016) findings offer important directions for sport marketing research. As the author notes, fan passion is a viable tool to segment sport consumers and aids in explaining consumptive behaviors, such as game attendance. Yet research has shown, even for fans who are motivated to attend, constraints exist which may hinder attendance (Pritchard, Funk, \& Alexandris, 2009; Trail \& Kim, 2011). Understanding how constraints affect fans with different degrees of passion for a team will allow marketers to adjust their strategies to potentially assist fans with an interest in attending games to better negotiate their constraints.

\section{Constraints to Attendance}

A primary thrust of sport marketing research has focused on understanding factors driving spectator consumption at sporting events (e.g., DeSchriver \& Jensen, 2002; Gitter \& Rhodes, 2010; Robinson, Trail, Dick, \& Gillentine, 2005; Simmons, Greenwell, Thorn, Hambrick, \& Greenhalgh, 2013; Zhang et al., 2001). While these studies offer insight into the motives and attributes affecting attendance, it would be inaccurate to assume nonattendance decisions are driven by the same set of factors (Tomlinson, Buttle, \& Moores, 1995). Understanding consumer constraints to attendance is relevant to marketers because constraints have the potential to limit or prevent patronage at sporting events (Kim \& Trail, 2010).

Much of the existing research on spectator constraints is guided by Crawford and Godbey (1987) and Crawford, Jackson, and Godbey (1991). The former proposed a conceptual framework for leisure constraints and, in so doing, categorized constraints as intrapersonal (psychological states/attributes such as stress, anxiety, accessibility of an activity, or one's socialization into an activity), interpersonal (relationship-related barriers such as partner, child, or friend interest/ lack of interest an activity), or structural (situational barriers including stage in family life cycle, financial and time-related resources, and weather). Crawford et al. (1991) expanded on these categories, proposing a hierarchical constraint model for leisure participation. In short, the authors argue intrapersonal constraints have the strongest influence on the decision to participate in leisure activities, as one's preference for an activity will not develop if intrapersonal constraints are present. For example, it is unlikely someone will attend a football game without having developed an interest in football or been previously socialized into the sport to some extent. Once an individual advances beyond intrapersonal constraints, they typically encounter interpersonal constraints. Returning to our example, even if someone has an interest in attending a game, and does not experience any other intrapersonal constraints, if no one is available with whom the fan can attend the game, she may face an interpersonal barrier inhibiting attendance. Structural constraints are only encountered once interpersonal constraints have been 
successfully negotiated. Despite interest from other family members in attending the football game, if it is raining on game day, or if our fan has to coach her child's soccer game, she may opt instead to watch the game on television. Crawford and colleagues' theoretical model suggests a hierarchical sequencing of constraints; however, according to the model, attendance at a sporting event would be contingent upon overcoming constraints at all three levels.

Recognizing the importance of such barriers in consumers' decisions not to attend sport, Kim and Trail (2010) identified four internal constraints (lack of sportrelated knowledge, lack of team success, lack of friends/spouse to attend game with, lack of interest in game from others) and seven external constraints (prior commitments, financial cost, alternative leisure activities, venue location, parking accessibility, sport participation alternatives, and sport spectator alternatives) which could conceivably have a negative influence on sport consumption. Among professional women's basketball spectators, lack of team success and alternative leisure activities were significant negative predictors of attendance. More recently, Trail and Kim (2011) considered the moderating effect of constraints on the relationship between motives and attendance. Results supported a moderated model in which certain constraints had a diminishing effect on motivations to consume; however, the authors acknowledged additional work is necessary to tease out specific interactions between motivating and constraining constructs. Regardless, both internal (lack of team success, lack of someone to attend with, and lack of interest from others) and external constraints (financial cost, parking accessibility, and venue location) hindered attendance intentions for intercollegiate women's basketball among a university's booster club members.

Others have also examined constraints inhibiting sport consumption. Pritchard et al. (2009), for example, asked members of Major League Baseball team loyalty programs to identify the one factor that most frequently prevents them from attending games in person. Reported internal constraints consisted of other priorities and physical issues such as being sick or tired. External constraints included financial and time commitments, inability to get tickets or good seats, parking and traffic issues, and diminished game appeal due to weather and opponent. Further, ANOVA results indicated those with constraints attended significantly fewer games than those reporting no constraints on their attendance.

\section{College Student Constraints}

As noted earlier, average student attendance at college football games has been declining nationwide. This is concerning as current students are often viewed as the suppliers of future revenue streams for college athletics departments. Due to the concerns of their members, the National Association of Collegiate Marketing Administrators (NACMA) commissioned three studies to examine student attendance behaviors (Guerra, 2015; Havard, Ryan, \& McGee, 2017; NACMA, 2016). Results from these studies suggest schoolwork, game time, weather, team performance, work, and ticket accessibility are the most commonly cited reasons students do not attend football games. The at-home viewing experience, traffic at the games, and lack of interest in football were also influential factors preventing attendance. Despite having more than 11,000 responses for each of these analyses, the constraint-related results lump all students into a homogenous group, failing to 
account for differences based on variables such as passion, year in school, or school type/conference affiliation.

Within academia, scholars have placed an emphasis on the motives and attributes affecting college student sport attendance (e.g., Ferreira \& Armstrong, 2004; Perrault, 2016; Swanson, Gwinner, Larson, \& Janda, 2003). To our knowledge, only five studies have been conducted examining constraints with student populations (Havard \& Dwyer, 2012; Lee \& Bang, 2011; Mayer, Morse, Eddy, \& Love, 2017; Simmons, Popp, McEvoy, \& Howell, 2017; Trail, Robinson, \& Kim, 2008). A notable theme emerging from these analyses were efforts to understand how constraints affected various student populations differently. For example, Trail et al. (2008) found that when it comes to football game attendance, males are significantly more constrained by other sport entertainment options and lack of team success compared to females, whereas weather was a more relevant constraint to females in the study. Havard and Dwyer (2012) noted differences in constraints to men's basketball game attendance based on prior basketball experience. Not surprisingly, those with prior experience (either having attended a game previously or played basketball in high school) were significantly less constrained by lack of interest in basketball and arena/cost barriers. Lee and Bang (2011) tested for differences in constraint influence between National Collegiate Athletic Association (NCAA) Division level, as well as students' level of identification with their school's team. Mayer et al. (2017), meanwhile, tested two constraint models based on whether students had previously attended a women's college volleyball game on campus.

Most recently, Simmons et al. (2017) surveyed non-game-attending students during actual football games to assess the influence of 33 separate constraints on their decision not to attend. Results revealed multiple differences in constraint intensity based on conference tier affiliation of the school at the data collection site (Power 5, Group of 5, Football Championship Series), frequency of game attendance of respondents, and timing of when the decision not to attend was made. At Power 5 schools, for example, the time commitment to attend games was a more significant constraint to attendance for respondents than it was at Group of 5 or FCS schools. In terms of frequency of attendance, lack of student interest in pregame and in-game entertainment was a more significant constraint for students with no intentions to attend games that season, compared to those who planned to attend more frequently.

The aforementioned studies on student attendance constraints identified a litany of constraints inhibiting students from attending games. While understanding that prior commitments or weather or lack of knowledge about games is relevant to collegiate marketers, efforts to segment respondents on the basis of sex, frequency of attendance, identification, or NCAA Division level allows marketers to be strategic in their efforts to help fans negotiate potential constraints they face.

\section{Study Purpose}

The current study seeks to expand our understanding of constraints inhibiting spectator attendance in several directions. First, college students are a population of interest for constraint research given the declining attendance at football games nationwide. Second, in line with the Simmons et al. (2017) study, this study will 
focus specifically on assessing constraints of non-game-attending students. Third, respondents will be segmented based on their passion for the team at their school of attendance. Differentiating based on passion will allow marketers to target students most likely to attend and focus their efforts on constraints most relevant to these groups. Therefore, the purpose of this study is to determine how constraints influence nonattendance decisions among college students with varying levels of passion for a college football team. The following research question was developed to guide this study's purpose:

RQ1: Are there differences in constraints to attending college football games among college students based on their level of passion for the home team?

\section{Method}

\section{Participants and Data Collection Procedures}

Data were collected from students on six college campuses across the Midwest and Southeast regions of the United States. Two of the data collection sites were schools representing NCAA Power 5 conferences (P5), two represented NCAA Group of 5 conferences (G5), and two were from NCAA Football Championship Series conferences (FCS). The researchers utilized intercept sampling to recruit students on/near campus during a football game hosted by their school of attendance to assess reasons why they chose not to attend that day's game. Survey distribution locations included tailgate lots following kick-off, dormitory lobbies, campus recreation centers, campus cafeterias, Greek housing, nearby sports bars, and student unions. Each location was selected as a place where students with a possible interest in attending the game might be located as opposed to the stadium. To be included in the study, respondents had to be a current student at the school of the data collection site, and not in attendance at the ongoing football game. Willing participants who met the inclusion criteria were given a paper/pencil questionnaire to be completed and collected on site.

\section{Instrument}

The survey instrument consisted of 50 questions, divided into four sections, designed to assess attendance constraints, football game attendance frequency and intentions, passion for the team, and demographics. The constraint subscale consisted of 33 constraints (Simmons et al., 2017), and was adapted from prior sport consumption constraint-related research and existing constraint measures (Ferreira \& Armstrong, 2004; Guerra, 2015; Kim \& Trail, 2010, NACMA, 2016; Pritchard et al., 2009; Trail et al., 2008). Internal and external constraints, grouped into six broad categories, were represented: (a) marketing-related (e.g., beverage cost, food cost, lack of interest in pregame/in-game entertainment, lack of awareness), (b) prior commitments (e.g., school commitments, friend commitments, work commitments), (c) intrapersonal factors (e.g., lack of interest in football, perceived difficulty socializing at games, perceptions of violence in football, poor experience at prior games), (d) event-specific factors (e.g., time commitment to attend, team performance, opponent quality, weather), (e) stadium- 
related variables (e.g., traffic, stadium accessibility, seating comfort, Wi-Fi availability), and (f) substitution options (follow along on social media, watch game on television, watch other games). The complete list of constraints included in the study can be found in Table 1. Respondents were asked to indicate their level

\section{Table 1 Constraint Mean Scores (Whole Sample)}

\begin{tabular}{|c|c|c|}
\hline Constraint & Mean Score (SD) & Category \\
\hline School commitments & $4.03(2.29)$ & Prior commitment \\
\hline No interest in football & $3.47(2.37)$ & Intrapersonal \\
\hline Friend commitments & $3.43(2.17)$ & Prior commitment \\
\hline Follow game via social media/online & $3.41(2.07)$ & Substitution \\
\hline Beverage cost & $3.25(2.19)$ & Marketing-related \\
\hline Watch game on TV & $3.19(2.05)$ & Substitution \\
\hline Time commitment to attend & $3.09(2.09)$ & Event-specific \\
\hline Food cost & $3.06(2.13)$ & Marketing-related \\
\hline Traffic/parking & $2.99(2.10)$ & Stadium-related \\
\hline Time of day & $2.89(2.02)$ & Event-specific \\
\hline Low student interest & $2.83(2.00)$ & Event-specific \\
\hline Work commitments & $2.80(2.21)$ & Prior commitment \\
\hline Not a fan of the team & $2.79(2.12)$ & Intrapersonal \\
\hline Team performance & $2.78(1.94)$ & Event-specific \\
\hline No interest in pregame festivities & $2.76(2.02)$ & Marketing-related \\
\hline No interest in in-game entertainment & $2.73(1.99)$ & Marketing-related \\
\hline Opponent quality & $2.66(1.94)$ & Event-specific \\
\hline Seating comfort & $2.57(1.80)$ & Stadium-related \\
\hline Watch other games on TV & $2.50(1.96)$ & Substitution \\
\hline Family commitments & $2.42(1.89)$ & Prior commitment \\
\hline Don't like concessions & $2.38(1.79)$ & Marketing-related \\
\hline Stadium accessibility & $2.36(1.95)$ & Stadium-related \\
\hline Didn't know about game & $2.35(2.04)$ & Marketing-related \\
\hline Seating location & $2.31(1.72)$ & Stadium-related \\
\hline Significant other commitment & $2.31(1.96)$ & Prior commitment \\
\hline Weather & $2.28(1.72)$ & Event-specific \\
\hline Nobody to go to game with & $2.25(1.74)$ & Intrapersonal \\
\hline Inappropriate fan behavior & $2.24(1.72)$ & Intrapersonal \\
\hline Wi-Fi accessibility & $2.24(1.85)$ & Stadium-related \\
\hline Ticket cost & $2.24(1.83)$ & Marketing-related \\
\hline Difficult to socialize & $2.11(1.63)$ & Intrapersonal \\
\hline Poor experience at a prior game & $2.03(1.63)$ & Intrapersonal \\
\hline Football is too violent & $1.82(1.54)$ & Intrapersonal \\
\hline
\end{tabular}


of agreement/disagreement with 33 statements concerning the extent to which each constraint impacted their decision not to attend that day's football game. All constraint items were measured using a 7-point Likert scale with anchors of strongly disagree/strongly agree. Additionally, a single open-ended question was included, asking "What is the main reason you chose not to attend today's football game?" This question was added for two reasons: (1) to triangulate the quantitative data and (2) to identify any additional constraints inhibiting student attendance beyond those included on the questionnaire.

Wakefield's (2016) four-item fan passion scale was included to measure student passion for their school's football team, and has been shown to be a valid and reliable measure of the construct of interest in limited work $(\alpha=.96$; AVE $=$ .89 ; square root of AVE= .94). Wakefield developed the scale to be a more parsimonious measure of obsessive and harmonious passion (Vallerand et al., 2003). The four items adapted for this study included: (a) What is your level of passion for team name football (No passion/Ultimate passion)?; (b) During your free time, to what degree does team name occupy your mind (never on my mind/ Always on my mind)?; (c) How much do you prioritize your time so that you can follow team name (None at all/Very much)?; and (d) When it comes to team name football, how do you feel (I can live without it/I can't live without it)? Each item was measured on a 7-point scale.

\section{Data Analysis}

Multivariate analysis of variance (MANOVA) was employed to identify significant differences in constraint intensity based on fan passion. A series of six MANOVAs were conducted, one for each constraint group category identified above. A tri-partite split was used to group respondents based on their passion for the team (low, moderate, high). Respondents with passion mean scores at 2.00 and below were categorized as low passion, 2.01-3.99 were categorized as moderate passion, and 4.00 and above were categorized as high passion. These cutoffs were determined in an effort to (a) maintain relatively equal cell sizes for purposes of MANOVA and (b) truly reflect different degrees of fan passion for practical interpretation. A frequency analysis of constraint responses was also conducted.

Open-ended data were subjected to a content analysis in an effort to "identify core consistencies and meanings" from the qualitative data collected (Patton, 2002, p. 453). Two cycles of coding were conducted. First, each author independently coded responses, labeling each response with a descriptive code (Miles, Huberman, \& Saldaña, 2014). As the primary purpose of this data was to identify any additional constraints beyond the 33 tested, an inductive approach to coding was utilized. After the first cycle of coding, the authors were in agreement on 374 of the 408 responses $(91.67 \%)$, demonstrating high intercoder reliability (Kassarjian, 1977; Miles et al., 2014). The authors discussed discrepancies in the remaining 34 responses, and made adjustments to initial descriptive codes until $100 \%$ agreement was reached. Following this process, a second cycle of coding was conducted for the purpose of grouping descriptive codes into similar categories/themes for analysis (Miles et al., 2014). 


\section{Results}

\section{Descriptive Statistics}

Of the 511 questionnaires distributed across the six sites, a total of 472 usable questionnaires were returned (92.37\% response rate). Males made up $48.73 \%$ of the sample. The sample skewed toward underclassmen, with freshman and sophomores cumulatively accounting for $54.47 \%$ of respondents. In terms of ethnicity, 246 respondents were White/non-Hispanic (52.12\%), 58 were White/ Hispanic (12.29\%), 53 were Asian (11.23\%), and 49 were Black (10.38\%). Nearly two-thirds of respondents $(63.77 \%)$ lived on campus. Regarding conference tier affiliation, 136 students attended a Power 5 school (28.81\%), 201 attended a Group of 5 school (42.58\%), and 135 were from Football Championship Series schools $(28.60 \%)$.

For purposes of MANOVA, respondents were grouped based on their passion for their school's team. Those in the low-passion group $(n=193)$ had an overall mean fan passion score of 1.34 (out of 7). Moderately-passionate fans $(n=153)$ had an overall passion mean of 2.94, while the overall passion mean for those indicating high levels of passion $(n=101)$ was 5.11. ANOVA was conducted to ensure the three groups represented significantly different levels of passion for the home teams $(F[2,444]=1,295.30, p<.001)$. The Cronbach alpha coefficient for the passion scale was .91. In terms of attendance, highly-passionate fans indicated their intentions to attend significantly more football games during the season $(M=$ 3.40) than moderately-passionate (2.55) and low-passion fans (0.97).

Constraint mean scores for the entire sample (Table 1) were relatively low overall. Prior school commitments was the highest rated constraint (4.03 out of 7), followed by no interest in football (3.47), prior friend commitments (3.43), following the game on social media/online (3.41), and beverage cost at the facility (3.25). Five of the six intrapersonal constraints were among the lowest rated, along with Wi-Fi accessibility (2.24) and ticket cost (2.24).

\section{MANOVA Results: Constraints $\times$ Passion}

Statistically significant multivariate main effects were detected for three of the six constraint types: intrapersonal constraints (Wilks's $\Lambda=.756, F[14,852]=9.130$, $p<.001$ ), event-specific constraints (Wilks's $\Lambda=.910, F[12,854]=3.455, p<$ .001 ), and marketing-related constraints (Wilks's $\Lambda=.853, F[14,842]=4.958$, $p<.001)$. Regarding intrapersonal constraints, subsequent univariate analyses revealed statistically significant univariate effects of passion on no interest in football $(F[2,432]=356.261, p<.001)$ and not a fan of the team $(F[2,432]=$ $224.157, p<.001)$. Not surprisingly, respondents in the low-passion group were significantly more constrained by their lack of interest in football $(M=4.47, S D=$ 2.48) than moderate $(M=3.11, S D=2.10)$ or highly-passionate fans $(M=2.23$, $S D=1.79)$. A similar pattern was detected with the not a fan of the team constraint.

Opponent quality $(F[2,432]=42.114, p=.003)$ and time commitment to attend $(F[2,432]=47.048, p=.004)$ were event-specific constraints where statistically significant univariate differences were found based on passion for the team. The attractiveness of the opponent appears to be a more intense barrier for 
highly-passionate $(M=3.00, S D=1.98)$ and moderately-passionate fans $(M=$ 2.90, $S D=1.89)$ than those with less passion for the team $(M=2.32, S D=$ 1.89). Less-passionate fans, however, are much more constrained by the amount of time necessary to attend a game in person $(M=3.47, S D=2.18)$ than highlypassionate fans $(M=2.66, S D=1.96)$.

Statistically significant univariate main effects were found on five of the seven marketing-related constraints. Don't like concessions $(F[2,427]=28.781, p=$ $.012)$ and ticket cost $(F[2,427]=38.816, p=.003)$ were stronger constraints for highly-passionate fans (concessions: $M=2.86, S D=2.12$; tickets; $M=2.67, S D=$ 2.03) than their less-passionate counterparts. Conversely, the constraints of no interest in pregame festivities $(F[2,427]=59.320, p=.001)$, no interest in in-game entertainment $(F[2,427]=80.742, p<.001)$, and didn't know about the game $(F[2$, $427]=38.547, p=.009)$ were strongest for the least passionate fan grouping. Means scores reported by low-passion fans for each were $3.19(S D=2.22), 3.25$ $(S D=2.29)$, and $2.66(S D=2.33)$, respectively.

\section{Frequency Analysis}

Despite numerous differences, mean scores for both the overall sample and withinpassion groupings were relatively low. As a result, interpretation of the results becomes more challenging. For example, even though highly-passionate fans are significantly more constrained by their lack of preference for concessions compared to less-passionate fans, this group's mean score for this constraint was only 2.86 (out of 7) - a number of limited utility for practitioners. An alternative approach to analyzing the data, which may yield more pragmatic results, is a frequency analysis of the percentage of students in each passion group for which an individual constraint negatively affects their decision to attend (that is, the percentage of respondents indicating a 5.00 or higher for each constraint tested). Table 2 shows these frequencies broken down by passion level.

Among highly-passionate fans choosing not to attend their school's football game, nearly a third indicated that beverage costs at the facility and the ability to

\section{Table 2 Percentage of Respondents Indicating a $\mathbf{5 . 0}$ or Greater (Out of 7) for Each Constraint}

\begin{tabular}{lccc}
\hline & \multicolumn{3}{c}{ Fan Passion } \\
\cline { 2 - 4 } & $\begin{array}{c}\text { Low } \\
\mathbf{( n = 1 9 3 )}\end{array}$ & $\begin{array}{c}\text { Moderate } \\
\mathbf{( n = 1 5 3 )}\end{array}$ & $\begin{array}{c}\text { High } \\
\mathbf{( n = 1 0 1 )}\end{array}$ \\
\hline Stadium-related & & & \\
Wi-Fi accessibility & 8.81 & 14.38 & 23.76 \\
Traffic/parking & 29.02 & 25.50 & 18.81 \\
Seating location & 10.36 & 10.46 & 12.87 \\
Seating comfort & 13.99 & 13.07 & 20.79 \\
Stadium accessibility & 19.17 & 15.03 & 18.81 \\
\hline & & & (continued)
\end{tabular}




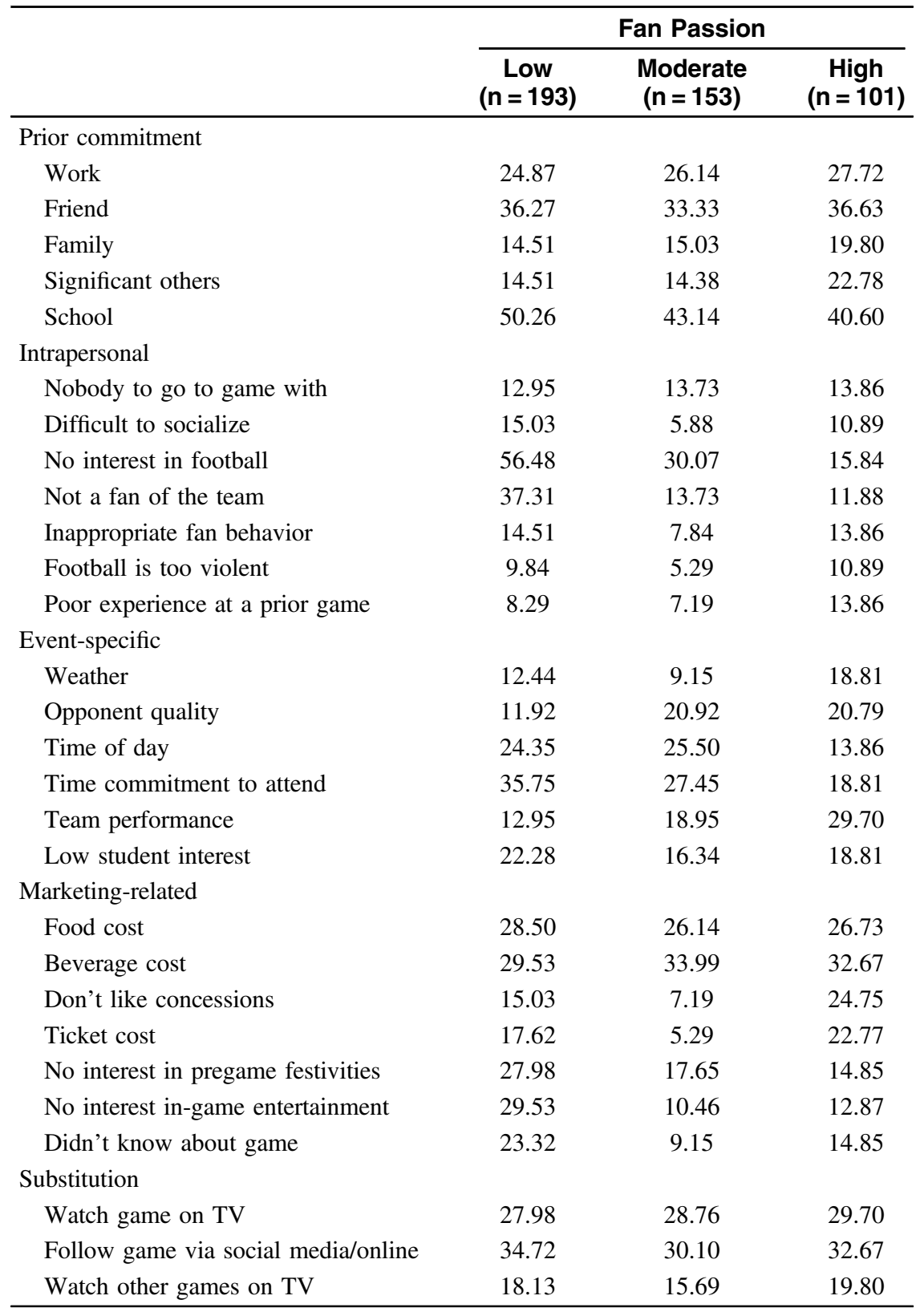


follow the game on social media strongly affected that decision. Poor team performance was also a highly-rated constraint for $29.70 \%$ of highly-passionate respondents. On the other end of the spectrum, more than a quarter of low-passion students were constrained by their lack of interest in pregame $(27.98 \%)$ and ingame $(29.53 \%)$ entertainment options. More than $23 \%$ of these fans did not even know a game was going on at the time of data collection, compared to $9.15 \%$ and $14.85 \%$ for moderate- and high-passion respondents, respectively. Low-passion fans are also heavily constrained by prior school commitments; however, more than $40 \%$ of high-passion fans also were strongly impeded by this barrier.

\section{Qualitative Results}

Based on the responses to the open-ended question, the most frequently cited reason for not attending the game during the time of data collection was apathy toward the game/team. Nearly a quarter of the 408 respondents to complete this section of the questionnaire reported some degree of apathy in the form of lack of interest in the game, boredom, forgetting that there was a game, or, in three cases, disgust toward the role of athletics in a university setting. Prior commitments were broken down by school (16.42\% of responses), social $(7.35 \%)$, work $(6.13 \%)$, and unspecified commitments $(6.86 \%)$. Commitments related to school and social settings were among the top four most frequently cited constraints. Examples of comments falling into these prior commitments categories included, "I have a test on Monday I have to study for", "prior commitment with friend who is more important than football", and "I am working during today's game."

Game accessibility, team quality, and poor game-day atmosphere were among the remaining constraint themes emerging from the open-ended data, garnering at least $5 \%$ of responses. Accessibility comments included, "I have difficulty getting to the stadium" and "Didn't bring my [student ID] card." Comments categorized as team quality included, "I would rather watch a good team" and "Not competitive enough." Finally, examples of responses categorized as poor game day atmosphere included, "It's always pretty crowded", "Too noisy", and "It can be boring."

The only new constraint coming out of the qualitative analysis was linked to consuming alcohol. The desire to consume alcohol rather than attend, either in a tailgate or other social setting, was recorded by 48 students $(11.76 \%)$. Illustrative participant responses of alcohol-related constraints included, "Would rather day drink" and "I want to tailgate and party." A complete list of qualitative themes and frequency breakdowns can be found in Table 3 .

\section{Discussion}

The current study sought to segment consumers based on fan passion (Wakefield, 2016) to better understand how constraints to attendance affect college students' decision not to attend football games. Recent nationwide trends indicate student attendance at college football games is in decline (Cohen, 2014). Understanding the barriers inhibiting attendance, and how those barriers vary based on one's passion for the team, allows marketers to better tailor their efforts to the needs of fans most likely to attend games. As noted above, the issue of constraints affecting 


\section{Table 3 Qualitative Themes of Constraints Inhibiting Student Attendance}

\begin{tabular}{lcl}
\hline Constraint Theme & $\begin{array}{c}\text { Frequency } \\
\text { (Percent Overall) }\end{array}$ & Type \\
\hline Apathy & $98(24.02)$ & Internal \\
Prior commitment (school) & $67(16.42)$ & External \\
Alcohol & $48(11.76)$ & External \\
Prior commitment (social) & $30(7.35)$ & External \\
Prior commitment (unspecified) & $28(6.86)$ & External \\
Accessibility & $27(6.62)$ & External \\
Team quality & $27(6.62)$ & External \\
Prior commitment (work) & $25(6.13)$ & External \\
Poor game-day atmosphere & $22(5.39)$ & External \\
Unaware of game & $11(2.70)$ & Internal \\
Weather & $8(1.96)$ & External \\
No one to go to game with & $6(1.47)$ & External \\
Transportation & $6(1.47)$ & External \\
Time commitment of game & $5(1.23)$ & External \\
Total & 408 & \\
\hline
\end{tabular}

college student game attendance has received prior attention, both in academia and industry (Guerra, 2015; Havard \& Dwyer, 2012; Havard et al., 2017; Lee \& Bang, 2011; Mayer et al., 2017; NACMA, 2016; Simmons et al., 2017; Trail et al., 2008); however, the current study advances this line of work by addressing many of the limitations in prior research.

First, the inclusion of fan passion offers new opportunities to detect differences between relevant college student fan segments. Others have segmented based on prior attendance (Havard \& Dwyer, 2012; Mayer et al., 2017; Trail et al., 2008), sex (Trail et al., 2008), conference tier affiliation (Lee \& Bang, 2011; Simmons et al., 2017), and timing of nonattendance decisions (Simmons et al., 2017). Lee and Bang (2011) did differentiate based on level of identification; however, the results were not specific to football, and data were collected from students in a classroom setting. The same was true for Trail et al. (2008), Mayer et al. (2017), and Havard and Dwyer (2012), although the latter did also collect data from residence hall meetings. An inherent drawback to utilizing classroom sampling in a study examining constraints to football attendance is that it relies on respondent memory from several days/weeks ago, or projections on future attendance decisions. In the prior studies, students were asked to try to remember the impact constraints had on their decision to attend earlier events. In the current study, data were collected from nonattendees at six different schools using intercept sampling during games. Given that constraints influence nonattendance decisions, surveying nonattendees directly about that decision may be a more appropriate approach to avoid issues with memory bias. Finally, the effects of each 
of the 33 constraints from the Simmons et al. (2017) analysis were tested in this study. This allows for the true effect of each constraint to be assessed, as opposed to structural equation modeling or factor analysis, in which some constraints may load onto a single factor but represent different barriers. For example, in the Havard and Dwyer study, the arena/cost constraint included four items: distance to the arena, inconvenient location, cost of attendance, and perceptions of neighboring area. While all four loaded onto the same factor, cost to attend, distance traveled, and concerns of the arena neighborhood are fundamentally different constraints. Teasing out these differences is important for practitioners.

One of the most interesting findings from the data centers on time. Significant differences were not detected on any of the prior commitment constraints regardless of passion level. Prior commitments to school and friends were among the most highly-rated constraints for all three passion groups. There was a statistically significant difference, however, between low- and high-passion fans related to the time commitment to attend games. Highly-passionate fans do not see sitting through a 3-hr (or more) game, plus tailgating, and dealing with traffic, to be as big of a constraint as less-passionate fans. Obviously, marketers want to build passion among their fan base; however, the reality is some fans will always be less passionate, and time is an important currency for this group as it relates to game attendance. Efforts to lure less-passionate fans to football games may need to start with shortening the experience or providing more value for this group. Pregame events may not be the solution, as lack of interest in pregame festivities was one of the more highly-rated constraints for low-passion respondents, and only adds to the time commitment of attending a game.

The significant difference between highly- and moderately-passionate fans on ticket cost as a constraint is also telling. Moderately-passionate fans represent the best target for marketers to consider, as highly-passionate student fans are already attending when they can. The data bore this out as high-passion respondents intended to attend significantly more games than less-passionate fans. Marketers may rely too frequently on ticket price discounts to attract fans, but the data presented in this study suggests that for moderately-passionate student fans, ticket cost is not a barrier. In fact, for this group, ticket cost was the second lowest-rated constraint behind perceptions that football is too violent. In most cases, student tickets are already greatly discounted; however, there is some research suggesting paying for tickets makes one more likely to attend (Arkes \& Blumer, 1985). Marketers may consider charging a nominal fee for student tickets in cases where tickets are free.

That is not to say price discounts would not work in other areas. Beverage cost at games was a highly-rated constraint for roughly a third of respondents in each passion grouping. Knowing this percentage of fans is strongly affected by a given constraint provides marketers with a starting point for helping students negotiate that barrier. Perhaps beverages at games could be priced lower for those with valid student identification (and valid age identification for alcoholic purchases). Aside from apathy toward the game and prior commitments, alcohol consumption was the top response given in the qualitative data, suggesting students want to drink, but do not see the game as an avenue to do that, likely due to price or unavailability. Marketers may want to consider the impact alcohol sales could have on student attendance, something schools are exploring more frequently (Dodd, 2016). 
Alcohol was not being sold in football stadiums at four of the six data collection sites included in this study, and, of the 48 respondents to indicate alcohol consumption was the primary inhibitor to game attendance, $30(62.5 \%)$ came from schools where alcohol sales are prohibited.

From a theoretical perspective, it may be time to change the way spectator constraints are studied. As noted above, constraint mean scores overall were relatively low. Students are not typically affected by 33 different constraints simultaneously, but only one or two at a time, resulting in the large majority of constraints being rated low, bringing down mean scores. Havard and Dwyer (2012), Lee and Bang (2011), Mayer et al. (2017), and Trail et al. (2008) reported similarly low mean scores in their studies. Rather than surveying sport consumers to assess the strength of each constraint in isolation, future research should consider employing conjoint analysis to allow respondents to make trade-offs across a set of constraints to determine the comparative importance of each (Aiken \& Koch, 2009; Ninomiya, 2015).

Additionally, it may be time for constraint research to advance beyond identifying relevant constraints, and dig further to uncover more specific factors keeping fans from attending. It does little use to know that a student is not attending a game because of prior commitments to friends. This constraint exists outside of a marketer's control. Instead, it would be useful to ask what the student is doing with his/her friend and if that is something which can be offered or recreated at the sport venue. Knowing students do not like concessions is important but does not give marketers enough information to help them change strategies. Regarding time commitments, current research does not pinpoint whether games are too long, or if students have others things to do which they prioritize over attending a game.

Fan passion appears to be a useful segmentation tool for analyzing constraints. Although fan passion is a "separate and distinct" (Wakefield, 2016, p. 231) construct from identification, it is well established that fans with varying levels of identification with a team attend games for different reasons (Trail et al., 2003). The same can be said for fan passion and reasons why people do not attend sport. Statistically significant differences on constraints affecting attendance were found in the current study based on passion for the home team. Scholars would be wise to include a passion measure in future studies along these lines.

Passion is also an important form of segmentation for college marketers to consider when developing strategies to attract students to football games. Traditionally, students are viewed as a single homogenous group. Results from this study suggest that not only do students vary in passion for their home football team, but constraints inhibiting attendance vary based on passion levels as well. Marketers should consider offering different products or product features to address relevant student constrains. One possibility could be to offer high-passion student fan segments better seats, accessibility to reliable Wi-Fi, and improved concessions items - as the data suggests, these factors serve as inhibitors to attendance. Ticket cost was a stronger constraint for high-passion fans as well; however, by adding value as suggested above, this group may be more willing to pay for tickets. Conversely, low-passion fans are constrained by traffic/parking and the time commitment necessary to attend. A possibility exists to offer shuttle services on and around campus during halftime to ferry low-passion fans to the game, lessening the effect of these constraints on this group. 
Opponent quality was another constraint where differences existed based on passion. Perhaps not surprising given that no interest in football was the most highly-rated constraint among low-passion fans, this group also reported being constrained to a lesser degree by the attractiveness of a game opponent than moderately- or highly-passionate respondents. This speaks further to the notion that marketers must enhance the value of attending a game for their most likely attendees (i.e., high- and moderate-passion consumers) by assisting them in negotiating constraints within the control of the athletic marketing staff (i.e., improved food and beverage costs/offerings, Wi-Fi accessibility, seating comfort), as some games will naturally be less desirable than others, based on scheduling. Repositioning game attendance for students around the holistic experience, which includes but is not limited to the game/opponent, may cause students to reevaluate the importance placed on opponent quality when making attendance decisions.

Marketers have an opportunity to collect passion data from freshman upon entry into college, along with contact information, to allow for more targeted segmentation efforts. Data presented here indicates low-passion fans are not as interested in pregame or in-game entertainment. Efforts to conduct focus groups with low-passion fans on campus to identify the types of activities and entertainment options they would like to see before and during games may draw lesserpassionate fans to attend games more frequently. Likewise, not attending due to lack of awareness of games is a constraint within the direct control of college athletic marketers. By conducting additional research on these market segments, practitioners can learn how students with varying degrees of passion prefer to get their information about athletic events.

A few limitations in the current study are worth mentioning. One of the things that differentiated this study from its predecessors examining student constraints to attendance were the data collection techniques employed, namely surveying nonattending students during actual games to ascertain the constraints most affecting their decision not to attend. The data only reflect constraints inhibiting attendance at that single game. Constraints may vary week to week. Further, some constraints, such as stadium accessibility, ticket costs, Wi-Fi accessibility, and seating location, are likely to be venue-specific. On-campus stadiums will always be more accessible to students than off-campus stadiums. Marketers and academics must be cognizant of such unique barriers at each institution when interpreting results. Additionally, as noted in the methods, data collection locations were strategically chosen in an effort to gather data from students with a possible interest in attending football games (e.g., tailgate lots, nearby sports bars, Greek housing, etc.). As such, data may not be representative of student populations as a whole. Constraints such as no interest in football and not a fan of the team, for example, may be more highly rated with a truly random sample.

\section{Conclusion}

Not all students are the same. When it comes to attending college football games, a multitude of constraints have been found to inhibit attendance. Those constraints vary, however, based on students' passion for their school's team. Strategies to 
assist students in overcoming these constraints will only be effective to the extent to which marketers are able to identify passion segments and address constraints most relevant to each group. While it appears scholars have identified an exhaustive list of game-related constraints (i.e., Kim \& Trail, 2010; Simmons et al., 2017; Trail et al., 2008), each school poses unique barriers for collegiate marketers to consider. As marketers struggle to reverse the trend of declining student attendance at football games, recognizing and addressing reasons why students do not attend, and how those reasons differ based on students' passion toward the program, may challenge college marketers to rethink the event experience and what it could be.

\section{References}

Aiken, K.D., \& Koch, E.C. (2009). A conjoint approach to investigating factors in initial team preference formation. Sport Marketing Quarterly, 18(2), 81-91.

Arkes, H.R., \& Blumer, C. (1985). The psychology of sunk cost. Organizational Behavior and Human Decision Processes, 35(1), 124-140. doi:10.1016/0749-5978 (85)90049-4

Cohen, B. (2014, August 27). At college football games, student sections likely to have empty seats. The Wall Street Journal. Retrieved from http://www.wsj.com/articles/atcollege-football-games-student-sections-likely-to-have-empty-seats-1409188244

Cowlishaw, T. (2018, February 15). Why falling student attendance at college football games is a real concern. . Is TV to blame? SportsDay. Retrieved from https:// sportsday.dallasnews.com/college-sports/collegesports/2018/02/15/falling-studentattendance-college-football-games-real-concern-tv-blame

Crawford, D.W., \& Godbey, G. (1987). Reconceptualizing barriers to family leisure. Leisure Sciences, 9(2), 119-127. doi:10.1080/01490408709512151

Crawford, D.W., Jackson, E.L., \& Godbey, G. (1991). A hierarchical model of leisure constraints. Leisure Sciences, 13(4), 309-320. doi:10.1080/014904091095 13147

DeSchriver, T.D., \& Jensen, P.E. (2002). Determinants of spectator attendance at NCAA division II football contests. Journal of Sport Management, 16(4), 311-330. doi:10. 1123/jsm.16.4.311

Dodd, D. (2016, June 27). Alcohol: Coming soon to a college football stadium near you. Retrieved from http://www.cbssports.com/college-football/news/alcohol-comingsoon-to-your-college-football-stadium-if-its-not-there-already/

Donahue, E.G., Rip, B., \& Vallerand, R.J. (2009). When winning is everything: On passion, identity, and aggression in sport. Psychology of Sport and Exercise, 10(5), 526-534. doi:10.1016/j.psychsport.2009.02.002

Ferreira, M., \& Armstrong, K.L. (2004). An exploratory examination of attributes influencing students' decisions to attend college sport events. Sport Marketing Quarterly, 13(4), 194-208.

Funk, D.C., \& James, J.D. (2001). The psychological continuum model: A conceptual framework for understanding an individual's psychological connection to sport. Sport Management Review, 4(2), 119-150. doi:10.1016/S1441-3523(01)70072-1

Gitter, S.R., \& Rhodes, T.A. (2010). Determinants of Minor League Baseball attendance. Journal of Sport Economics, 11(6), 614-628. doi:10.1177/15270025093 59758

Guerra, A. (2015). Student attendance at collegiate sporting events: Comprehensive report. National Association of Collegiate Marketing Administrators. 
Havard, C.T., \& Dwyer, B. (2012). Examining university students' constraints to attendance at college basketball games. Journal of Contemporary Athletics, 6(4), 203-217.

Havard, C.T., Ryan, T.D., \& McGee, M.S. (2017). Report on college student attendance at collegiate athletic events. National Association of Collegiate Marketing Administrators.

Hong, J. (2009). A comparison of motivational factors affecting attendance between avid and casual fans at minor hockey games. International Journal of Sport Management and Marketing, 5(1/2), 115-131. doi:10.1504/IJSMM.2009.021754

James, J., \& Trail, G.T. (2008). The relationship between team identification and sport consumption intentions. International Journal of Sport Management, 9(4), $427-440$.

Kassarjian, H.H. (1977). Content analysis in consumer research. Journal of Consumer Research, 4(1), 8-18. doi:10.1086/208674

Kim, Y.K., \& Trail, G. (2010). Constraints and motivators: A new model to explain sport consumer behavior. Journal of Sport Management, 24(2), 190-210. doi:10.1123/jsm. 24.2.190

Kim, Y.K., Trail, G., \& Ko, Y. (2011). The influence of relationship quality on sport consumption behaviors: An empirical examination of the relationship quality framework. Journal of Sport Management, 25(6), 576-592. doi:10.1123/jsm.25.6.576

Koo, G., Andrew, D.P.S., Hardin, R., \& Greenwell, T.C. (2009). Classification of sports consumers on the basis of emotional attachment: A study of minor ice hockey fans and spectators. International Journal of Sport Management, 10(3), 307-329.

Lee, C., \& Bang, H. (2011). Comparison of division I and division III intercollegiate spectators: Motives and constraints. International Journal of Leisure and Tourism Marketing, 2(2), 159-175. doi:10.1504/IJLTM.2011.038887

Mael, F., \& Ashforth, B.E. (1992). Alumni and their alma mater: A partial test of the reformulated model of organizational identification. Journal of Organizational Behavior, 13(2), 103-123. doi:10.1002/job.4030130202

Mayer, K.C., Morse, A.L., Eddy, T.W., \& Love, A. (2017). Constraint factors affecting nonattendance in collegiate volleyball. International Journal of Sport Management and Marketing, 17(3), 182-199. doi:10.1504/IJSMM.2017.10006501

Miles, M.B., Huberman, A.M., \& Saldaña, J. (2014). Qualitative data analysis: A methods sourcebook (3rd ed.). Thousand Oaks, CA: Sage Publications.

NACMA. (2016). Drivers of fan advocacy and home game attendance. Westlake, OH: Author.

Ninomiya, H. (2015). Price elasticity of ticket demand in the professional basketball league in Japan: A case study of simulating ticket purchase rates using conjoint analysis. Sport Marketing Quarterly, 24(4), 246-257.

Patton, M.Q. (2002). Qualitative research \& evaluation methods (3rd ed.). Thousand Oaks, CA: Sage Publications.

Perrault, E.K. (2016). Attitudes and motivations of students toward athletic-event attendance at a midsize division III university: Recommendations for communicators. International Journal of Sport Communication, 9(3), 321-339. doi:10.1123/ijsc.2016-0011

Pritchard, M.P., Funk, D.C., \& Alexandris, K. (2009). Barriers to repeat patronage: The impact of spectator constraints. European Journal of Marketing, 43(1/2), 169-187. doi: 10.1108/03090560910923283

Raynor, G. (2017, October 9). Clemson keeps winning, but where are the students during games? The Post and Courier. Retrieved from https://www.postandcourier.com/sports/ clemson-keeps-winning-but-where-are-the-students-during-games/article_6948d796ad3a-11e7-98be-f37383c6d87e.html 
Robinson, M.J., Trail, G.T., Dick, R.J., \& Gillentine, A.J. (2005). Fans vs. spectators: An analysis of those who attend intercollegiate football games. Sport Marketing Quarterly, 14(1), 43-53.

Simmons, J.M., Greenwell, T.C., Thorn, D.F., Hambrick, M.E., \& Greenhalgh, G.P. (2013). Consumption of niche sports: Understanding which product attributes predict consumption across different levels of team identification. International Journal of Sport Management and Marketing, 13(3/4), 239-256. doi:10.1504/IJSMM.2013. 059723

Simmons, J., Popp, N., McEvoy, C., \& Howell, S. (2017). Tomorrow's fans gone today: Assessing constraints to student attendance at college football games. Journal of Applied Sport Management, 9(3), 13-23.

Stewart, B., Smith, A.C.T., Nicholson, M. (2003). Sport consumer typologies: A critical review. Sport Marketing Quarterly, 12(4), 206-216.

Swanson, S.R., Gwinner, K., Larson, B.V., \& Janda, S. (2003). Motivations of college student game attendance and word-of-mouth behavior: The impact of gender differences. Sport Marketing Quarterly, 12(3), 151-162.

Tomlinson, M., Buttle, F., \& Moores, B. (1995). The fan as a customer: Customer service in sports marketing. Journal of Hospitality \& Leisure Marketing, 3(1), 19-36. doi:10. 1300/J150v03n01_03

Tracy, M. (2016, September 30). To put more students in the seats, colleges cue the D.J. The New York Times. Retrieved from https://www.nytimes.com/2016/10/02/sports/ ncaafootball/to-put-more-students-in-the-seats-colleges-cue-the-dj.html?_r=0

Trail, G.T., \& Kim, Y.K. (2011). Factors influencing spectator sports consumption: NCAA women's college basketball. International Journal of Sport Marketing \& Sponsorship, 13(1), 60-71.

Trail, G.T., Robinson, M.J., Dick, R.J., \& Gillentine, A.J. (2003). Motives and points of attachment: Fans versus spectators in intercollegiate athletics. Sport Marketing Quarterly, 12(4), 217-227.

Trail, G.T., Robinson, M.J., \& Kim, Y.K. (2008). Sport consumer behavior: A test for group differences on structural constraints. Sport Marketing Quarterly, 17(4), 190-200.

Vallerand, R.J. (2008). On the psychology of passion: In search of what makes people's lives most worth living. Canadian Psychology, 49(1), 1-13. doi:10.1037/0708-5591. 49.1.1

Vallerand, R.J., Blanchard, C., Mageau, G.A., Koestner, R., Ratelle, C., Leonard, M., . . . Marsolais, J. (2003). Les Passions de l'Âme: On obsessive and harmonious passion. Journal of Personality and Social Psychology, 85(4), 756-767. PubMed ID: 14561128 doi:10.1037/0022-3514.85.4.756

Vallerand, R.J., Ntoumanis, N., Philippe, F.L., Lavigne, G.L., Carbonneau, N., Bonneville, A., . . . Maliha, G. (2008). On passion and sports fans: A look at football. Journal of Sport Sciences, 26(12), 1279-1293. doi:10.1080/02640410802123185.

Vallerand, R.J., Rousseau, F.L., Grouzet, F.M.E., Dumais, A., Grenier, S., \& Blanchard, C.M. (2006). Passion in sport: A look at determinants and affective experiences. Journal of Sport and Exercise Psychology, 28(4), 454-478. doi:10.1123/jsep.28.4.454

Verner-Filion, J., Lafreniere, M.K., \& Vallerand, R.J. (2012). On the accuracy of affective forecasting: The moderating role of passion. Personality and Individual Differences, 52(7), 849-854. doi:10.1016/j.paid.2012.01.014

Wakefield, K. (2016). Using fan passion to predict attendance, media consumption and social media behaviors. Journal of Sport Management, 30(3), 229-247. doi:10.1123/ jsm.2015-0039

Wann, D.L., \& Branscombe, N.R. (1993). Sports fans: Measuring degree of identification with their team. International Journal of Sport Psychology, 24(1), 1-17. 
Wann, D.L., Melnick, M.J., Russell, G.W., \& Pease, D.G. (2001). Sport fans: The psychology and social impact of spectators. New York, NY: Routledge.

Wheeler, W.D. (2017, September 26). What does Missouri State have to do for students to attend football games? Springfield News-Leader. Retrieved from https://www. news-leader.com/story/sports/college/msu/2017/09/26/what-does-missouri-state-havedo-students-attend-football-games/677277001/

Zaichkowsky, J.L. (1985). Measuring the involvement construct. The Journal of Consumer Research, 12(3), 341-352. doi:10.1086/208520

Zhang, J.J., Pease, D.G., Lam, E.T.C., Belerive, L.M., Pham, U.L., Williamson, D.P., \& Wall, K.A. (2001). Sociomotivational factors affecting spectator attendance at minor league hockey games. Sport Marketing Quarterly, 10(1), 43-54. 